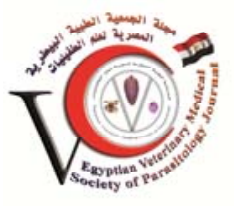

Original Article

\title{
Identification of Trypanosoma species infecting equine in Egypt using Polymerase Chain Reaction (PCR)
}

Ibrahim GH Radwan, Souzan G Ghattas Parasitology Department, Animal Health Research Institute, Dokki, Giza, Egypt

\begin{abstract}
:
This study was carried out to identify the Trypanosoma species in symptomatic and asymptomatic horses and donkeys in Egypt by using polymerase chain reaction (PCR). Blood samples were collected from 80 horses and 37 donkeys from different farms and private owners at Cairo and Giza governorates. Thin blood smears were prepared from each sample and examined microscopically. Four samples for Trypanosoma species were positive by using microscopic examination of stained blood smears from horses. While, all samples collected from donkeys were negative for Trypanosoma species infection. Microscopic examination of stained thin blood smears revealed that the parasite were monomorphic thin trypomastigote parasite, long free flagellum and thin posterior extremity with subterminal small kinetoplast and length ranges from 18-34 micron (mean 26). The four positive samples from horses were subjected to PCR using three sets of Trypanosoma species specific primers (T. brucei group, $T$. evansi and T. equiperdium). Three of the 4 positive samples showed symptoms of Trypanosoma infection and one case asymptomatic. PCR assay. identified that the 4 samples were positive for T. brucei group and Trypanosoma evansi species using Trypanosoma brucei TBR 1/TBR 2 specific primer at $164 \mathrm{bp}$ and T. evansi EVA $1 / 2$ specific primer at $138 \mathrm{bp}$ While, the same four samples showed negative results using T. equiperdium Nade 5 specific primer at $395 \mathrm{bp}$. Six negative samples from horses and donkeys examined microscopically were subjected to PCR examination. These samples were negative for the three species of Trypanosoma. From this it can be concluded that, PCR assay was a highly sensitive diagnostic technique, for exact discrimination between the species of Trypanosoma infection (T. brucei group, T. evansi and T. equiperdium) in equines. Therefore, Trypanosoma infection in horses in Egypt is most probably due to T. evansi.
\end{abstract}

Key words: Trypanosomosis; equine; diagnosis; PCR

\section{INTRODUCTION}

Equine trypanosomosis is an economically important arthropod-borne disease caused by Trypanosoma species. The disease produces negative effects on health that decreases the productivity of horses. The parasite can infect different host species and is mechanically transmitted by different biting flies such as Tabanidae and Stomxys spp. as well as by vampire bats (FAO, 1998). The other role of carrier animals can be emphasized by the fact that sever form of the disease occurs in horses and camels, whereas, cattle and buffalo are considered important reservoirs of the infection for equines (Soulsby, 1982). Equines are very susceptible to the infection and death can occur within weeks or months (Stephen, 1986). In Africa trypanosomosis caused by $T$. evansi is one of the most important disease of camels and horses. Their most significant impact possibly comes from the chronic form where abortion, infertility, reduced weight gain and lower work output are the common sequel of the infection. Surra in equines was usually acute occasionally chronic with remittent fever associated with parasitemia. Urticarial eruptions appear on the skin, edematous plaques developed on the ventral surface of the body, swelling of legs and petechial hemorrhage occurred on mucous membranes. The infected horses lost weight in spite of retaining their appetite with hair luster but muscular weakness and progressive paralysis occurred (AbdelWahhab, 2005). T. evansi makes an animal unable to perform its duty in a proper manner; slowly and gradually the victim moves towards death (Muteed et al., 2010). These three species are considered to be the most pathogenic trypanosomes infecting equines and causing disease that is referred to as nagana, dourine and surra, respectively (Claes et al., 2003). T. evansi is evolved from 
T. brucei due to the loss of Kinetoplast DNA and is considered as petite mutant of Trypanosoma brucei (Lai et al., 2008; Field and Carrington 2009). Hence, the names Trypanosoma brucei brucei, Trypanosoma brucei equiperdum and Trypanosoma brucei evansi were proposed. Diagnosis of Trypanosoma species usually starts with clinical symptoms or the detection of antibodies to Trypanosoma species conclusive evidence of Trypanosoma infection, however, relies on detection of the parasite in the blood or tissue fluids of infected animals.

Unfortunately, parasitological techniques can not always detect ongoing infections as the level of parasitemia is often low and fluctuating, particularly during the chronic stage of the disease (Cales et al., 2004). As an alternative to parasitological tests, DNA detection based on PCR has been proposed. The development of a PCR test that would be able to differentiate between the different members of the trypanozoom subgenus still remains a challenging issue (Touratuer, 2000). The others include DNA amplification tests such as polymerase chain reaction (PCR) as described in OIE (OIE, 1996) and DNA probes as suggested by Uilenberg (1998). The PCR procedure is extremely sensitive as even minute quantities of parasite DNA can be amplified into a detectable quantity if the number of cycles is sufficiently high. The PCR is a highly sensitive and specific method that has been widely used for the detection of trypanosomes (Venture et al., 2002). Though PCR has been reported to be more sensitive than conventional parasitological techniques (Aslam et al., 2010), however, most of PCR assays have not been validated under field conditions for the diagnosis of natural infection (Clausen et al., 1998). However, the sensitivity of specificity of different available primers is varying (Pruvot et al., 2010).

The aim of the present study was initiated to investigate the Trypanosoma spp. in equine, isolation of Trypanosoma DNA and identification of the isolated strain by using molecular technique (PCR) in Egypt.

\section{MATERIALS AND METHOdS}

\section{Collection of samples:}

Blood samples were collected from each of 80 horses and 37 donkeys for detection of trypanosome species infection. These samples were collected from different farms and private owners at Cairo and Giza governorates. The samples were collected from jugular vein and placed in sterile tubes containing ethylene diamine tetra-acetic acid (EDTA) as anticoagulant. The samples were used for blood smears and PCR techniques.

\section{Parasitological examination:}

The horses and donkeys investigated clinically. Thin blood smears were prepared from each collected samples, fixed by methanol and stained with Giemsa stain (Kelly, 1979). The parasites were identified according to the characters described by Soulsby (1982).

\section{Samples for PCR:}

The positive blood samples for trypanosome spp. (horse samples) and 6 Trypanosoma negative samples (3 horses and 3 donkeys samples) were subjected to isolation of Trypanosoma DNA and identification of the isolated strain by using PCR amplification. Three sets of specific primers were used for identification of trypanosome species in equines; TBR1/2 for $T$. brucei groups, Nad5 $1 / 2$ for $T$. equiperdium and EVA1/2 for T. evansi.

\section{DNA extraction:}

One $\mathrm{ml}$ of positive Trypanosoma blood samples were collected in tubes containing $0.1 \mathrm{ml}$ anticoagulant (EDTA). Samples were processed as described by Barker et al. (1992). Briefly, $500 \mathrm{ml}$ of saponin lysis buffer $(0.22 \% \mathrm{NaCl}$, $0.015 \%$ saponin, $1 \mathrm{mM}$ EDTA) were added to $50 \mathrm{ml}$ of blood, and the mixture was then centrifuged at $10,000 \mathrm{~g}$ for $1 \mathrm{~min}$. at $41^{\circ} \mathrm{C}$. Pellets were washed three times with the same volume of lysis buffer, resuspended in $100 \mathrm{ml}$ of PCR buffer $(50 \mathrm{mM} \mathrm{KCl}, 10 \mathrm{mM}$ Tris- $\mathrm{HCl}, \mathrm{pH} 8.0,0.5 \%$ Tween $20,100 \mathrm{mg}$ of proteinase $\mathrm{K}$ per $\mathrm{ml}$ ), and incubated at $56^{\circ} \mathrm{C}$ for 1 hour. After an incubation of $10 \mathrm{~min}$. at $95^{\circ} \mathrm{C}$, $5 \mathrm{ml}$ of the supernatant were used directly in the PCR.

\section{Polymerase chain reaction (PCR) amplification:}

Three sets of primers were used and mentioned in table (1). PCR reaction were performed as described by Ljaz et al. (1998) for T. brucei groups, Njiru et al. (2004) for $T$. evansi and Li et al. (2007) for T. equiperdium. The reaction containing $50 \mathrm{mM} \mathrm{Kcl}, 10 \mathrm{~m} \mathrm{M}$ tris- $\mathrm{Hcl}$ (ph 8.3), $4 \mathrm{mM}$ $\mathrm{MgCl}_{2}, 0.1 \%$ Triton $\mathrm{x} 100,200 \mu \mathrm{M}$ of the deoxynucleotide triphosphate (dNTPs) mix (Gibco BRL, USA), 2 units of Tag polymerase enzyme (Promega Company, Madison, USA), 80 pmole of each primer and $5 \mu$ of processed blood samples. The reactions were performed in an automatic DNA thermal cycler (Perkin-Elmer, California) with a three steps cycling program as follows: 35 cycles, each cycle consisted of a denaturing step at $95^{\circ} \mathrm{C}$ for 1 minutes, annealing step at $52^{\circ} \mathrm{C}$ for 1 minute and extension at $72^{\circ} \mathrm{C}$ 
Table 1: Primers sequences: Oligonucleotide primers (5-3) used for Trypanosoma species gene amplification

\begin{tabular}{|c|c|c|c|c|}
\hline T. species & Primer & Sequences* & Product (bp) & References \\
\hline \multirow[t]{2}{*}{ T.brucei } & TBR 1 & F (5\GAATATTAAACAATGCGCAG3\) & 164 & Ljaz et al. (1998) \\
\hline & TBR 2 & R (5\CCATTTATTAGCTTTGTTCG 3\) & & \\
\hline \multirow[t]{2}{*}{ T. equiperdium } & Nad5 1 & F (5\TGGGTTTATATCAGGTTCATTTATG 3\) & 395 & Li et al. (2007) \\
\hline & Nad5 2 & R (5\CCCTAATAATCTCATCCGCAGTACG 3\) & & \\
\hline \multirow[t]{2}{*}{ T. evansi } & EVA 1 & F (5\- ACATATCAACAACGACAAAG -3\) & 138 & Njiru et al. (2004) \\
\hline & EVA 2 & R (5\- CCCTAGTATCTCCAATGAAT -3\) & & \\
\hline
\end{tabular}

*The arrangement of deoxynucleotide-triphosphat; C: Cytosine; A: Adenine; T: Thiamine and G: Guanine

Table 2: Results of microscopic examination

\begin{tabular}{lcccc}
\hline Animals & \multicolumn{2}{c}{ Symptomatic } & \multicolumn{2}{c}{ Asymptomatic } \\
\cline { 2 - 5 } & No. & +ve & No. & +ve \\
\hline Horses & 6 & 3 & 74 & 1 \\
Donkeys & 1 & - & 36 & - \\
\hline
\end{tabular}

for 1 minute. The amplified fragments were visualized by electrophoresis in a $2 \%$ TAE agarose gel containing ethidium bromide $(0.5 \mu \mathrm{g} / \mathrm{ml})$ run at $90 \mathrm{~V}$ for 1 hour with $25 \mu$ of PCR reaction loaded. 50 bp DNA Ladder RTU marker (Cat. No DMO 12- R 500-Gene DireX, USA) was used a molecular weight standard.

\section{RESULTS}

\section{Parasitological results:}

The clinical signs recorded on the investigated 80 horses and 37 donkeys were fever, anemia, corneal opacity, emaciation and diarrhea. Four samples for Trypanosoma species were positive by using microscopic examination of stained blood smears from horses. While, all samples collected from donkeys were negative for Trypanosoma species infection. Three horses out of the 4 positive cases shows symptoms and one case asymptomatic, while only one case of donkeys had symptoms (Table 2). The morphometric characters of the detected trypanosome species using Geimsa stained thin blood smears were monomorphic, long with pointed both extremities. The kinetoplast was small and subterminal with long free flagellum. Their length were varied from 18 to 34 micron (mean 26 micron) (Fig. 1).

\section{PCR results:}

Table (3) showed the results of 10 examined samples for Trypanosoma species by using PCR. PCR amplification identified 4 (horses) samples were positive for Trypanosoma species. The other 6 ( 3 horse and 3 donkeys samples) samples were negative for Trypanosoma species. The horse samples were positive for $T$. brucei groups using Trypanosoma brucei TBR 1/TBR 2 primer at 164 bp Fig. (2). The same positive samples gave positive by using $T$. evansi EVA $1 / 2$ primer at 138 bp (Fig. 3). All the same positive samples showed negative result with $T$. equiperdium using Nad 5 primer at 395 bp (Fig. 4).

Table 3: Results of PCR amplification

\begin{tabular}{|c|c|c|c|c|c|}
\hline \multirow{2}{*}{$\begin{array}{c}\text { No of } \\
\text { examined animals }\end{array}$} & \multirow{2}{*}{ Animals } & \multirow{2}{*}{ ME } & \multicolumn{3}{|c|}{ PCR } \\
\hline & & & T. brucei group & T. evansi & T. equiperdium \\
\hline 1 & Horse & + & + & + & - \\
\hline 2 & Horse & + & + & + & - \\
\hline 3 & Horse & + & + & + & - \\
\hline 4 & Horse & + & + & + & - \\
\hline 5 & Horse & - & - & - & - \\
\hline 6 & Horse & - & - & - & - \\
\hline 7 & Horse & - & - & - & - \\
\hline 8 & Donkey & - & - & - & - \\
\hline 9 & Donkey & - & - & - & - \\
\hline 10 & Donkey & - & - & - & - \\
\hline Total & & 4 & 4 & 4 & - \\
\hline
\end{tabular}




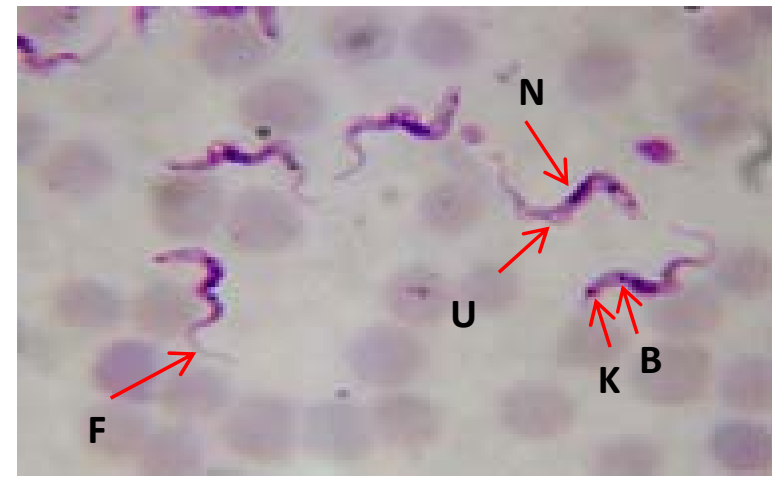

Figure 1: Trypanosoma species in thin blood film from horse (x100): K: Kinetoplast, B: Basal body, N: Nucleus, F: Free flagellum, U: Undulating membrane

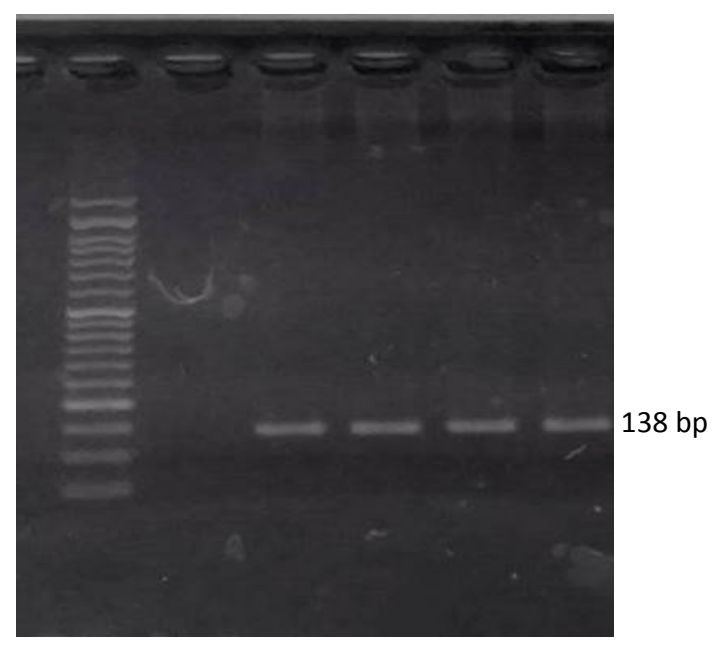

Figure 3: Agarose-gel electrophoresis of amplification products obtained from genomic DNA of species of horse using T. evansi specific primer (138 bp PCR product).

Lanes: M: molecular weight standard (50 bp )

Lane: 1,2,3,4 showed positive results for $T$. evansi

Lane : 5 showed negative result for $T$. evansi

\section{Discussion}

Equine piroplasmosis is of great importance due to the international movement of horses, especially for horses that travel to equestrian sports events. It remains frequently reported in veterinary clinics, especially at the season of flies 'burden. However, Little is known on the prevalence and distribution of Trypanosoma species causing equine trypanosomiasis in Egypt.

In the present study, the animals which infected with $T$. brucei subgroup $T$. evansi were clinically showed fever, anemia, corneal opacity, emaciation and diarrhea. These finding were in agreement with Soulsby (1982), Chaudhary and Iqbal (2000) and Abdel-Rady (2011). Examination of blood films in this study revealed that Trypanosoma species were monomorphic, long with

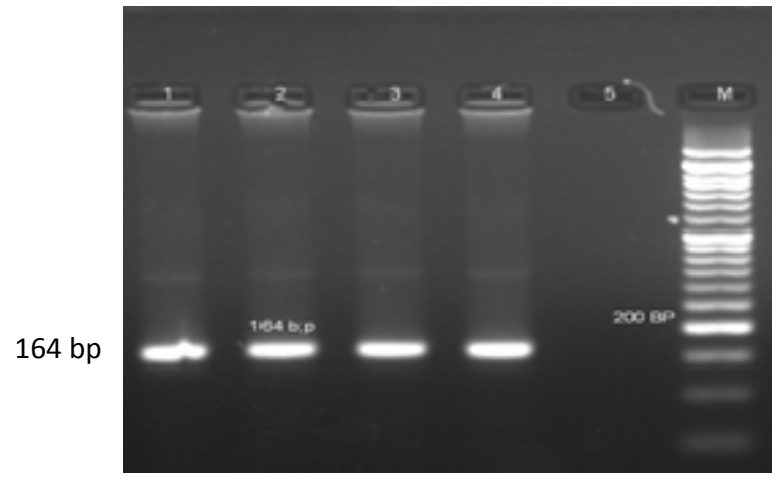

Figure 1: Agarose-gel electrophoresis of amplification products obtained from genomic DNA of Trypanosoma species of horse using $T$. brucei groups specific primer (164 bp PCR product). Lanes: M: molecular weight standard (50 bp) Lane : 1-4 : T. brucei isolate from horse. Lane : 5 showed negative result for $T$. evansi

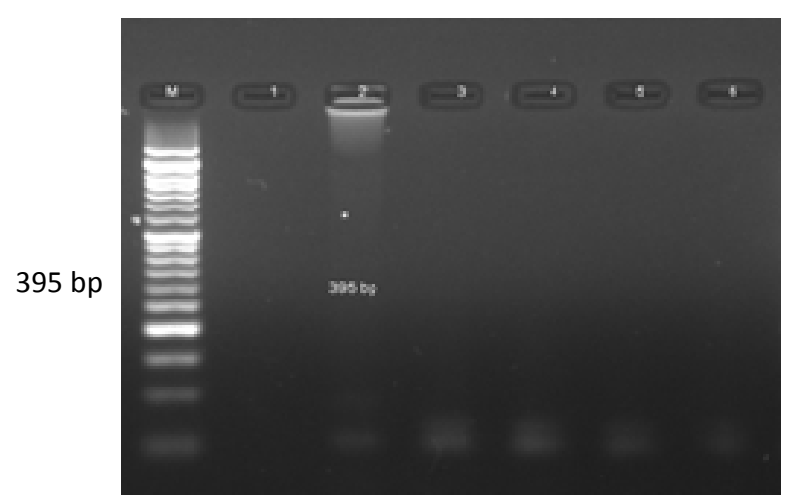

Figure 4: Agarose-gel electrophoresis of amplification products obtained from genomic DNA of species of horse using $T$. equiperdium specific primer (395 bp PCR product).

Lanes: M: molecular weight standard (50 bp)

Lane: 1-6 showed negative results for T. equiperdium.

pointed both extremities. The kinetoplast was small and subterminal with long free flagellum. Their length were varied from 18 to 34 micron (mean 26 micron). These results were in agreement with Soulsby (1982), Zayed et al. (2010) and Singh et al. (2014).

Various diagnostic techniques demonstrating the presence of trypanosome in the blood samples is widely used. These parasitological techniques are simple, rapid and provide a satisfactory sensitivity. However, the samples must be processed within 4-6 hours after collection, otherwise, parasites are dead and false negative results may be obtained. It, therefore, seems to be inconvenient to use the parasitological techniques in the field. Additionally, some of these techniques cannot always detect ongoing infections especially when the level of parasitemia either low or fluctuating (Nantulya, 1990). 
In another study, PCR showed a higher detection rate of trypanosomes that was about four times higher than with the parasitological techniques (Singh et al., 2004). PCR has some major advantages over the parasitological technique as the samples do not have to be processed within a short period after collection and can be delayed. The technique specially be useful when large number of animals need to be sampled during field surveys. Further, PCR could be an important tool for evaluating the efficacy of chemotherapy. Generally, the percentage of detection and the sensitivity of the PCR is variable depending upon the primers employed, which is determined by the number of copies and the homology of the primers with the target sequence (Fernández et al., 2009).

Concerning to the PCR assay, this study showed that all samples proved to be positive by thin blood films examination were also positive by PCR after using Trypanosoma species primers. PCR amplification identified 4 of 10 samples were positive for $T$. brucei groups using Trypanosoma brucei TBR 1/TBR 2 primer at $164 \mathrm{bp}$. The same positive samples gave positive by using T. evansi EVA $1 / 2$ primer at $138 \mathrm{bp}$. All the same positive samples showed negative result with $T$. equiperdium using Nad 5 primer at $395 \mathrm{bp}$. All samples collected from horses and donkeys showed negative result with $T$. equiperdium using specific primer for $T$. equiperdium, Nad 5 primer at $395 \mathrm{bp}$. All samples proved to be positive by microscopic examination using thin blood films were also positive using PCR assay. Moreover, in case of donkeys all samples were negative for $T$. brucei groups, $T$. evansi and $T$. equiperdium. Li et al. (2007) used PCR assay for the differentiation of $T$. brucei and $T$. equiperdium from $T$. evansi in horses and donkeys. They found the products of $395 \mathrm{bp}$ were amplified from all $T$. brucei and $T$. equiperdium samples tested using the Nad5-PCR, but not from $T$. evansi DNA samples or any of the control samples.

Claes et al. (2003) analyzed $10 T$. equiperdium, 8 T. evansi and $4 T$. brucei using random amplified polymorphic DNA (RAPD) and multiplex-endonuclease fingerprinting, a modified AFLP technique in samples collected from horses and donkeys. They found that the $T$. equiperdium strains were more related to $T . b$. brucei. They added the $2 T$. equiperdium strains are genuine $T$. equiperdium causing dourine; all other $T$. equiperdium strains actually are $T$. evansi causing Surra or T. equiperdium does not exist at all. In that case, different clinical outcome of horse infections with $T$. evansi or $T$. b. brucei is primarily related to the host immune response. Abdel-Wahhab (2005) reported one case of equine by using RAPD method in Egypt. Salim (2014) examined 509 samples collected from equines in Sudan to estimate the endemicity of equine trypanosomiasis using the generic Its I-PCR diagnostic methods. They found the horses and donkeys were infected by $T$. brucei subgroup, $T$. vivax, $T$. siamae and $T$. congolense at $250 \mathrm{bp}, 400 \mathrm{bp}$ and $700 \mathrm{bp}$ respectively. Pinchbeck et al. (2008) used PCR assay for the detection of $T$. brucei in equines. They found the prevalence of infection were $18 \%$ using PCR technique using ITS specific primer. Aslam et al. (2010) used the molecular (PCR) methods for diagnosis of Trypanosomal infection in equines. The PCR amplification was performed using a set of oligonucleotide primers (TBR1 and TBR2) contained 164 bp. Trypanosoma equiperdum causes the disease dourine exclusively in equines, and $T$. evansi causes Surra predominantly in livestock but also in other mammals including humans (Lun et al., 1993). While small numbers of new cases of dourine have been reported from countries, such as China, Kazakhstan, Kyrgyzstan, Pakistan, Ethiopia, Botswana, Namibia, South Africa, Brazil, Italy and Germany in the past decades, Surra is relevant in areas including Northeast Africa, Asia and South America (Maudlin et al., 2004).

In conclusion, the results obtained in this study suggested that, the using of PCR Trypanosoma specific primers was a highly sensitive diagnostic technique, for exact discrimination between the species of Trypanosoma infection (T. brucei groups, T. evansi and T. equiperdium) in equines. This will be useful tools for clarifying the epidemiology of equine trypanosomiasis in Egypt, so help to establish adequate control programs for flies and specific treatment for each Trypanosoma species. This indicate that the Trypanosoma species infesting equines in Egypt were most probably due to T. evansi species.

\section{REFERENCES}

Abdel-Rady, A. (2011): Epidemiological studies (parasitological, serological and molecular techniques) of Trypanosoma evansi infection in camels (Camelus dromedarius) in Egypt. Veterinary World 1(11):325-328.

Aslam, A.; Zafar I.C.; Habib, U.R.; Kamran, A.; Nasir, A. T.; Yaqub, A.M., Abdul, R.S. (2010): Comparative Evaluation of Parasitological, Serological and DNA Amplification Methods for Diagnosis of Natural Trypanosomal Infection in Equines. Pakistan J. Zool. 42(4):371-376

Azza, M. Abdel-Wahhab (2005): Studies on Trypanosoma species infecting equines in Egypt. Ph.D. pp. 123 
Barker, R.H.; Banchongaksorn, T., Courval, J.M.; Suwonkerd, W., Rimwungtragoon, K., Wirth, D.F. A. (1992): simple method to detect Plasmodium falciparum directly from blood samples using the polymerase chain reaction. Am J Trop Med Hyg 1992; 46:416-26.

Chaudhary, P.H. and Iqbal, M.J. (2000): Incidence, biochemical and haematological alterations induced by natural trypanosomiasis in racing dromedary camels. Acta Trop., 77:209-213.

Claes, E.C.; Agbo, M.; Radwanska, M.F.W.; Tepas, T.; Baltz, D.T.; Dewaal, B.M.; et al. (2003): How does Trypanosoma equiperdium fit into the Trypanozoon group? A cluster analysis by RAPD and Multiplex-endonuclease genotyping approach. Parasitology 126:425-431.

Claes, F.; Radwanska, M.; Urakawa, T.; Majiwa, P.A.; Goddeeris, B.M., Buscher, P. (2004): Variable surface glyco -protein RoTat 1.2 PCR as a specific diagnostic tool for the detection of T. evansi infection. Kinetoplastid Biol. Dis. 3:3. Clausen, P.H.; Wiemann, A.; Patzelt, R.; Kakaire, D.; Poetzsch, C.; Peregrine, A.; et al. (1998): Diagnosis of Trypanosoma evansi by the polymerase chain reaction (PCR). J. Protozool. Res. 8:204-21.

FAO (1998): A Field Guide for the diagnosis, Treatment, Prevention of African Animal Trypanosomiasis: chapter 5, Non Tsetse-transmitted trypanosomoses, 170pp.

Fernandez, D.; Gonzalez-Baradat, B.; Eleizalde, M.; Gonzalez-Marcano, E.; Perrone, T. and Mendoza, M., (2009): Trypanosoma evansi: A comparison of PCR and parasitological diagnostic tests in experimentally infected mice. Exp. Parasitol., 121: 1-7

Field, M.C. and Carrington, M. (2009): The trypanosome flagellar pocket, Nature rev Microbiol. 7:775-786.

Kelly, W.R. (1979): Veterinary Clinical Diagnosis, M.F. ElMekkawy, A.M. Monazie and X. Q. Zhu, $2^{\text {nd }}$ edition, Bailliere Tindall, London, 261-300.

Lai, D.H.; Hashimi, H.; Lun, Z.R; Ayala, F.J. and Lukes, J. (2008): Adaptation of Trypanosoma brucei to gradual loss of kinetoplast DNA :Trypanosoma equiperdium and Trypanosoma evansi are petite mutants of Trypanosoma brucei. Pioc. Natl. Acad. Sci. 105:1999-2004.

Li, F.J., Robin B.G., De-Hua L, Filip C.X.Z., Zhao-Rong L. (2007): PCR approach for the detection of Trypanosoma brucei and $T$. equiperdum and their differentiation from $T$. evansi based on maxicircle kinetoplast DNA. Molecular and Cellular Probes 21:1-7.

Ljaz, M.K.; Nurek. M.S.; Mouhamed, A.I. and Dar, F.K., (1998): Comparative studies on the sensitivity of polymerase chain reaction and microscopic examination for the detection of Trypanosoma evansi in experimentally infected mice. Comp Immunol Microbiol Infect Dis.;21 (3):215-23.

Lun, Z.R.; Fang, Y.; Wang, C.J. and Brun, R. (1993): Trypanosomiasis of domestic animals in China. Parasitol Today (9):41-5.

Maudlin, I. Holmes, P.H. and Miles, M.A. (2004): The trypanosomiases. Oxford-shire: CABI Publishing; Infect. Dis., 21:215-23.
Muteed, M.A.; Chaudhary, Z.I. and Shakoori, A.R. (2010): Comparative studies on the sensitivity of polymerase chain reaction (PCR) and microscopic examination for the detection of T. evansi in horses.

Njiru, Z.K; Robertson, I; Okaye, S.; Constantine, C.C; Ndung'u, J.M; Thompson, R.C.A., Reid, SA (2004): Detection of Trypanosoma evansi in camels using PCR and CATT/T. evansi tests in Kenya. Vet. Parasitol. 124(3-4):187199.

Nantulya, V.M. (1990): Trypanosomiasis in domestic animals: the problems of diagnosis. Rev. Sci. Tech. 9: 357367.

O.I.E. (1996): Manual of standards for Diagnostic Tests and Vaccines: $3^{\text {rd }}$ ed., Office International Des Epizooties, World Orgnization for animal Health.

Pinchbeck, G.L.; Morrison, L.J.; Tait, A.; Langford, J.; Meehan, L.; Jallow, S. et al. (2008): Trypanosomiasis in The Gambia: prevalence in working horses and donkeys detected by whole Genome amplification and PCR, and evidence for interactions between trypanosome species. http:// www.biomedcentral.com/1746-6148/4/7.

Pruvot, M. Kamyingkird, K.; Desquesnes, M.; Sarataphan, N. and Jittapalapong, S (2010): A comparison of six primer sets for detection of $T$. evansi by polymerase chain reaction in rodents and Thai livestock. Vet. Parasitol. $171: 185-193$.

Salim, B.; Mohammed A.B. and Sugimoto, C. (2014): Molecular detection of equine trypanosomes in the Sudan. Vet. Parasitol. 200: 246-250

Singh, N., Pathak, K.M.L. and Kumar, R., (2004): A comparative evaluation of parasitological, serological and DNA amplification methods for diagnosis of natural Trypanosoma evansi infection in camels. Vet. Parasitol., 126: 365-373.

Singh, M.B.; Singla, L.D.; Deep Deka; Ashuma; Filia, G. and Verma, R. (2014): Comparative sensitivity of different primers in detection of $T$. evansi infection in experimentally infected mice by Polymerase Chain Reaction vis-a-vis conventional parasitological techniques. International Journal of Advanced Research 2(11):10511062.

Soulsby, E.J.L. (1982): Helminthes, arthropod and protozoa of domesticated animals, $3^{\text {rd }}$ edition. Bailiere Tindall and Cassell Ltd., London (UK) 65p

Stephen, L.E. (1986): Trypanosomiasis. A. veterinary perspective Edit by: Stephen LE.Oxford, Pergamon Press.

Touratier, L. (2000): Challenges of non-tsetse transmitted animal trypanosomes (NTTAT) An outline and some perspectives Ann N Y. Acad. Sci. 916:237-239.

Uilenberg, G. (1998): A Field Guide for the Diagnosis, Treatment and Prevention of African Animal Trypanosomosis. Food and Agriculture Organization of the United Nations.

Venture, R.M.; Takeda, G.F.; Silva, R.A.; Nunes, V.L.B.; Buck, G.A. and Teixeira, M.M.G., (2002): Genetic relatedness among Trypanosoma stocks by random 
amplification of polymorphic DNA and evaluation of a synapomorphic DNA fragment for species-specific diagnosis. Int. J. Parasitol., 2: 53-63.
Zayed, A.A.; Habeeb, S.M.; Allam, N.A.T. and Ashry, H.M.Z. (2010): Critical Comparative study of parasitological and serological differential diagnostic methods of Trypanosoma evansi infections in some farm animals in Egypt. American-Eurasian J. Agric. \& Environ. Sci., 8 (6):633 $-642$. 